\title{
African Cinema
}

\author{
By Rod Stoneman
}

Spring 1994 Issue of KINEMA

\section{AFRICAN CINEMA: ADDRESSEE UNKNOWN}

Thirty years after Sembene's pioneering Borom Sarret, this is a moment of celebration but also of selfassessment for emergent African cinema -- an opportunity to think through questions of funding, the basis of production, and the way that various African films address their different audiences.

\section{Pieces of Identity}

In Europe and North America a nebulous imaginary unity is projected onto Africa. This lazily assumed misconception continues to underpin the distorting insularity and ignorance of the north. It is precisely an imaginary, implicit unity and not to be confused with the distinct political unity proposed by the project of Pan-Africanism, built from conscious political and cultural alliances. One does not have to be too familiar with the continent to understand that there are also many Africas -- culturally, politically, socially. Indeed more than a thousand languages are spoken in Africa and there are as many complex social systems, cultures and organisations of community life.

In the past African cinema has been depicted with a broad brush stroke mapping its productions onto wide geographic categorisations: northern, western and southern African cinemas. These cultural divisions are overlaid by colonial boundaries -- strange and arbitrary groupings -- but they constitute a set of relations which separate some countries and connect others. More attention could be devoted to articulating the complex categories of similarity and difference in Africa -- but all this can be said about Europe too -any attempts to edge the tectonic plates of a continent together that does not recognise the diversity and hybridity of its cultures is unlikely to succeed.

African cinema makes connections between such separations, drawing out correspondence and indicating differences. Films offer unexpected recognitions, bringing images into focus and debate. One thinks of the success of Ferid Boughedir's Tunisian film Halfaouine in Morocco and other muslim countries and the young South African who spoke movingly of being startled half way through Cissé's Yeleen, suddenly realising that he had never before watched half an hour of any film without white faces.

Most approaches to cultural and national difference in African cinema are made without reference to the questions of class and gender difference. It seems necessary to stress the shameful fact that over $90 \%$ of African cinema is still produced by men and that inevitably most of those that get to make films come from the urbanised educated elites of their respective countries.

African cinema has developed largely on auteurist lines with a predominance of directors who are also, at one and the same time, the producers of their own films. The same people conceive, write, raise the finance for, direct and produce most African movies -- and then they organise the festivals and run the magazines. Whilst this represents a welcome dissolution of the strict demarcations between roles in industrial cinema, at some point the lack of complementary specialisation may also be a disadvantage. A body of professional, entrepreneurial, cultural producers is badly needed to articulate potential funding sources and, it can also be argued, to strengthen individual production processes.

This artisanal basis condemns many directors to long gaps between their films; as the Senegalese film maker Gai Ramaka indicates -- "they have always gone on the long, solitary and laboured quest for international aid, accepting all its criteria and demands, making one film every 4 to 10 years." Then, when production eventually commences the directorial id has no producerial super-ego to keep an eye on the budget. This leads to questions about the way in which different production modes provide different bases for films to address their audiences. The scores of script writers and a heavily hierarchical production that industrial production brings to bear on every film produces a high degree of formula production -- versions of this can be seen in Indian and Hong Kong, and even Egyptian cinema. This is not to pose a reductionist either "industrial" or "individual" dichotomy for African cinema but to propose an examination of the spaces available. To win 
a cultural war with guerilla tactics it is necessary to navigate this terrain, and think through the way any mode of production effects what appears on the screen...

\section{Footnotes in dependence}

As a result of the cultural and political conservatism of virtually all African television the most vigorous production sector has come into being around feature film making in many countries. The complete lack of space for intelligent or imaginative work within television has increased the isolation and financial constraints of cinema on the continent. To some extent this also accounts for the concentration of feature production and the lack of creative documentary work in Africa, in comparison to Latin America and Asia for instance.

Although only available to a small, urban fraction of most populations the constraints of terrestrial television in Africa are serious. Unlike the foreign domination of cinema exhibition, up to this point the problems of television are more a matter of internal political blockage than external imposition. It is not primarily a question of financial resources although the constant and reliable supply of cheap western product has made real challenge more difficult. But as democratic movements in various countries demand airspace for the contending dynamics of a society as part of its transformation, gradually the first multi-national versions of foreign television intervention across the continent via satellite are making their appearance on the horizon.

Although one of the benefits of a concentration on features for cinema release has been an avoidance of governmental interference, the considerable budgetary and human resources involved in any cinematic enterprise inevitably places economic pressures on the independence of the producer. The major outside force at play in African cinema is French government finance in its several forms. The Ministry of Co-operation often provides 20-25\% of production budgets while the recently created Ecrans du Sud supports development, distribution and training. The effect of this sustained funding centred on francophone Africa can be seen in comparison with the uneven and debilitated development of other, say anglophone and lusophone, cinemas. Although there may be other geographical and cultural factors in this.

In response to the field of force exerted by French funding and longer term strategic aims it is imperative to extend and consolidate an interactive mosaic of funding. A range of financial sources should come into play in different, specific configurations. For each African film the "plan de financement" should be a balanced combination of monies from several disparate directions (indigenous and northern, television and cinema, commercial and state). Although considerable effort is necessary to draw these different sources of finance together, when achieved it guarantees a level of independence and wide dissemination. In this context the connection and co-operation of different African states in production and in supporting distribution and exhibition is still imperative. Ousmane Sembene's Camp de Thiraoye, made in 1987 with financial backing from Senegal, Tunisia and Algeria, is exemplary in this regard.

One of the dangers of a fixed dependency on a few limited sources of external finance is perhaps indicated by the French Ministry of Co-operation's recent, short-lived and inappropriate attempt to place a precredit sequence and logo "The Minister of Co-operation presents..." (plus a new version of Pathé's gallic cockerel?) on the films it part-funded. Nothing should be taken for granted, as Mikhail Gorbachev indicated in a reference to Heraclitus: "as the ancient Greeks say "everything flows, everything changes." Any source of funding can fade away as quickly as it arrived for distant and irrelevant reasons. Much of the current northern funding network was set up for other logics and motives, and operates within different dynamics, not necessarily relating to the needs of development of southern cinema. Last year TVE in Spain completely cut its 20 million dollar budget for co-production with Latin America and Channel Four has made severe reductions in the budgets for Third World feature work over the last two years. One cannot but wonder whether the result of the recent elections for the French National Assembly will effect funding strategies in this area.

Film-makers are now addressing the complex and pertinent issue of how money coming from the North affects or modifies the overall range of cinema in the South. Is there a unconscious predilection for certain kinds of product, a selective prioritisation of certain types of films? What kinds of African films are more difficult, or even impossible, for European television? Do specific interventions change particular films? No commutation test exists when asking how these relations may effect the organic development of African cinema -- it is not possible to know those films which have never been made! But perhaps it would be worth carrying out some research to produce an exact analysis of the proportion and typology of African films 
made with little or no northern funding.

It would be inappropriate to seek to dictate, or impose a "modelisation" -- in this context it is essential for northern funders to maintain a pluralistic, open attitude and develop their support for a wide range of forms and tendencies in film. It is the free contention of those varied tendencies that creates a healthy cinema culture. In Mao Tse Tung's elegant formulation: "Letting a hundred flowers blossom and a hundred schools of thought contend is the policy for promoting the progress of the arts." But such formulations are all too often merely rhetorical; as the sad example of the artistic regime in China itself indicates, governments habitually follow a more constrained route.

\section{In and Out of History}

In trying to track the influence of foreign funding a tentative typology of texts might be useful. One can approach the diversity and specificity of recent production through three (somewhat reductive) categories:

Village films -- this anthropological and folkloristic genre is generally imprecisely located in the precolonial epoch. Wend Kuuni is an exquisite and early example, more recently: Yaaba, Layla Ma Raison, Tilai have been very successful.

Modern social films -- in contrast these are marked by an engagement, in some form or another, with contemporary social reality: The Blue Eyes of Yonta, Bezness, Guelwaar. They may still be set in the village but they generally deal with some aspect of the effect of the city on that rural economy: Zanboko, Ta Dona, Sango Malo, Finzan, Disha, After the Storm and Tin Pis Run are equivalent examples from other parts of the world (India, Argentina and Papua New Guinea).

Magic realist films involve more of a formal departure from the constraints of the dominant mode of representation, the language and grammar of the classic narrative cinema which evolved in America and Europe in the first twenty years of this century. The term realist signifies the modern setting into which magic, the Other, erupts; connecting that reality with forms of specifically African culture and religion: Touki Bouki and Hyenas, Laada and Saaraba. Even though they are set in Europe, Africa am Rhein and Ama, an African Voyage of Discovery, in their invocation of the power of ancestors and contemporary manifestations of animism, can be seen as part of this genre.

There is a danger that the anthropological genre of "village films," more attractive to European cinema and television, potentially allows the magnetic pull of foreign audiences and foreign finance to effect the range and emphasis of African cinemas. The North's desire for "village films" can be connected with an underlying humanist ideology traceable to (at least) The Family of Man, a photographic exhibition organised and published by Life magazine just after the Second World War. It comprised images of humanity in all its diversity, juxtaposing photos of say an Inuit hunter from Canada with an Italian child, a Peruvian peasant with a Hong Kong taxi driver.

In the context of the immediately post-colonial era this exhibition was well-intentioned, asserting an underlying "common" humanity at a specific historical moment when the recently liberated nations were placing themselves on new and more equal terms internationally. The photographs of the myriad individuals seemed to say "different, but the same;" a meaning encased within strong connotations of the exotic produced by the extreme unfamiliarity and distance of the signified. But today at quite a different historical moment this same humanist enterprise effaces other sets of differences which underlie the New World Order, differences around the relative distribution of power, money and resources for instance. For how long can the richest $20 \%$ of the world continue to consume $80 \%$ of the world's goods and resources?

"Village films" also disavow the relations of history -- one of their defining characteristics is that they position their narratives outside history and outside time. It is this historical and social imprecision that allows them to fall more easily within the penumbra of humanism. "Modern social films" confront the society in which they are made, as do specific historical explorations like Med Hondo's Sarraounia and Haile Gerima's recent Sankofa, which represent a purposeful invocation of a historical moment in the face of the present. The West African bird which looks both forward and backward, in the title of Gerima's film, specifically invokes the role of the past in effecting the present and changing the future.

The recent genre of "village films" seem to inhabit the same humanist ideology as The Family of Man: the 
films may be read in their countries of origin as a reclamation of an image of pre-colonial history, sometimes engaging in a polemic with traditional values in contemporary society, but a western audience watching Yaaba recognises the adultery, the closeness between small children and a "grandparent" as asserting that humanity is the same here and there.

This is not to condemn or dismiss a whole genre, some examples such as Wend Kuuni, Yaaba and Layla, Ma Raison are strong pieces of cinema that have found wide resonance at home as well as abroad, but their success should be related to the complex questions of audience, reception and finance. A cinema which is not based on productive interaction with its own social context is displaced, adrift. The dangers of cultural production for export are also touched on by Adewale Maja-Pearce, following Ngugi wa Thiong'o, in his polemical critique of the Nigerian novel -- "continuing to write in 'European' languages perpetuates the colonial dependency that has brought the continent to its present point of collapse." The initial equilibrium between artistic aspirations and political aims in the founding declarations of the film-makers' organisation FESPACI seems to be less evident at this time, but anyone who is interested in the social role of cinema must always ask how do these films function and for whom?

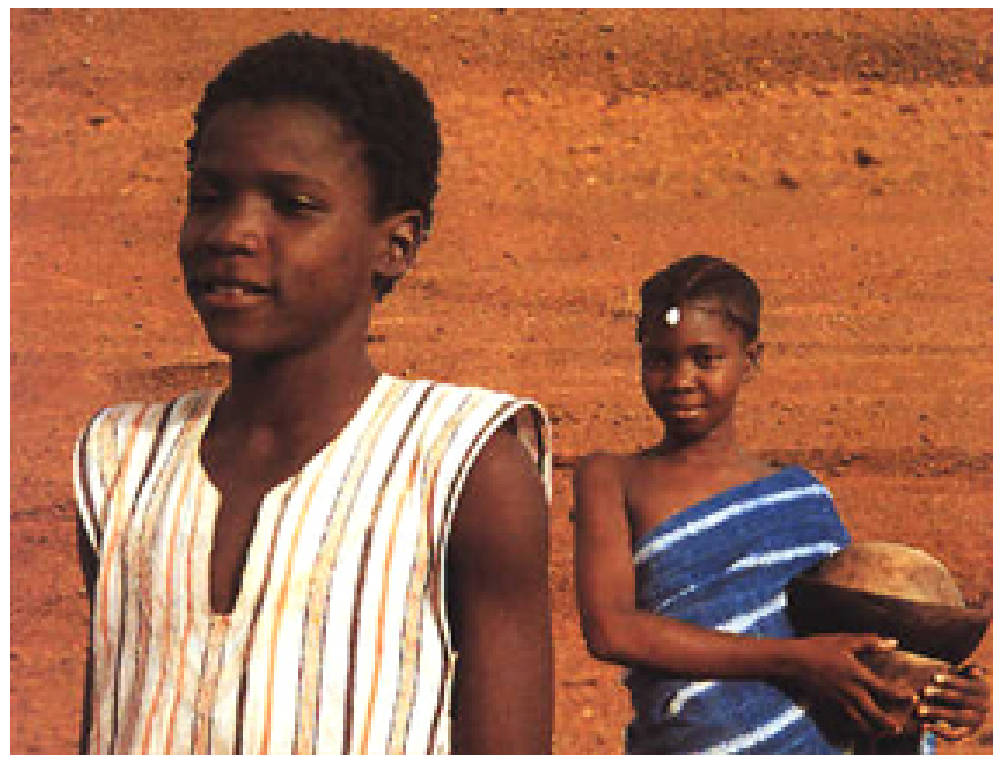

Figure 1: Yaaba (dir. Idrissa Ouedraogo, 1989)

\section{The Question of an audience}

Given the problems of distribution and exhibition in Africa perhaps it is not surprising that many filmmakers do not consciously connect themselves with the notion of specific audiences or think through the way that their films work with different publics at home and abroad. The high proportion of finance coming to productions from Europe exacerbates the problem and abstracts film production from its felt relationship with audiences. The proliferation of festivals of African cinema, many of them outside Africa, displace the moment of the film's reception, leading to a deeper confusion and the spurious notion of a "universal" audience.

The more urgent and concrete problems of distribution and exhibition in Africa have always been a serious infrastructural deficiency. As Flora Gomes put it "nowadays film-makers must think about African audiences...we must be able to produce and distribute in Africa to be closer to our public." It is to be hoped that gradually forms of South -- South distribution will grow up alongside the north-south axis. The problems of American cultural hegemony are considerable and they have become a global phenomenon, (of all the films shown in British cinemas in 1990 93\% were American). In this sense the pretensions and aspirations that say, the English and Italian cinema had to being "industries" are almost over -- European cinema also exists at an artisanal level now.

A film means different things to different audiences, it may be located very differently in separate cultural 
contexts -- in the country of its production and abroad. A film like Halfaouine shifts cultural space quite dramatically -- it is a strong example of popular cinema in Tunisia, breaking all box office records and out-grossing all American production in the year of its release. It made one third of its production cost $(600,000)$ back in its home market, although it was hardly distributed in sub-Saharan Africa (a return of only 5,000). But it is relocated in the space of "art cinema" when shown in Europe or America. Everything from the use of subtitles, the style of publicity, to the type of cinema buildings it is shown in, confines it to a socially limited audience. To some extent this is also true of the television spaces available; both Channel Four and BBC2 have specific young/male/middle class audience profiles -- part of the British speciality for anachronistic class distinctions.

\section{Desire for diversity}

One of the real strengths of African cinema in recent years has been its sustaining interaction with the fastchanging ferment of African culture and society, where, for example, many countries are starting to question the idea of the one-party state. There are intense debates about models and forms of democratisation, meanwhile urbanisation and the rapid transformation of rural communities continues apace; at the same time the relations between men and women, the open affirmation of other forms of sexuality are changing fast. A whole range of fresh possibilities and problems are developing at unprecedented speed.

The turbulence of this social maelstrom has its effect on cultural production and on different cinematic strategies. Cinema has had a relevant role in relation to the development of emancipatory, democratic desire on the continent -- as a means of exploring a contradictory process, provoking openings, challenging constraints and testing limits from Le Vent and Zanboko to, more recently, Allah Tantou or Sankara. Feature work has provided a space to restate fearlessly desires for free media as one way of countering corruption and tyranny. As Souleymane Cissé recently suggested "cinema should have a disruptive influence even in a democracy -- the new constitutions should include creative freedom and not only freedom of the press." In the long term the African cinema that is going to sustain its "disruptive influence" is not going to be built outside Africa. For it to have an effective social, cultural interaction it has to be built inside Africa by, with and for Africans.

(This article was originally prepared for a Symposium at the 1992 Carthage Film Festival in Tunis.)

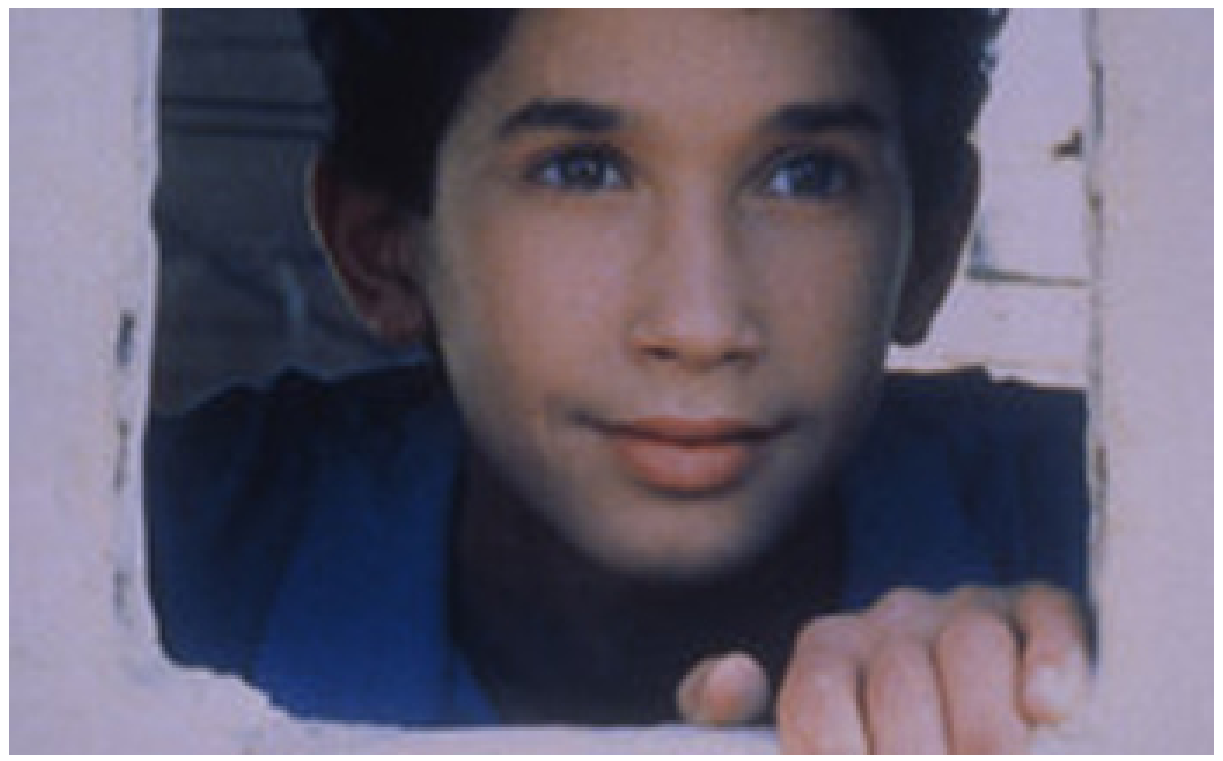

Figure 2: Halfaouine (dir. Ferid Boughedir, 1990) 


\section{Author Information}

Rod STONEMAN is Director to Huston School of Film and Digital Media, National University of Ireland in Galway. He previously served as Chief Executive of the Irish Film Board and a deputy commissioning editor of independent film and video at Channel Four. He has made several independent programmes for television (including "Between Object and Image," "Ireland: The Silent Voices," and "Italy: The Image Business"), written for Screen, Sight and Sound, Framework, and Afterimage. 